http://dx.doi.org/10.4314/gjl.v8i2.5

\title{
BILINGUALISM AND THE PSYCHOLOGY OF COLORS
}

\author{
Adebimpe Adegbite
}

\begin{abstract}
The reality of humans spans beyond spoken language into varieties of extra linguistic avenues such as colors, clothing, pictures and inscriptions through which they express themselves. Color system is a general concept across cultures even though distinction through names and ascribed meaning(s) to each color vary per culture. This research investigated the strong statements about identity and attitude that bilinguals can make through their choice of colors depending on how conducive they find their linguistic community. Comparison was made between Chinese-English bilinguals in the US and Yoruba-English bilinguals in Nigeria using Ethnolinguistic Vitality Theory of sociolinguistics (EVT). Findings revealed that Chinese-English bilinguals had an overwhelming positive evaluation of their native language while Yoruba-English bilinguals had a more positive evaluation of English. Also, the importance of an individual's language within their immediate environment can influence their evaluation of such language. Respondents utilized colors, as a universal concept, to reveal implicit information such as attitude and perception. The study concludes that language attitude can be largely presumed upon cognitive perception of a language based on influencing societal factors, and that EVT is very much applicable to beyond ordinary spoken utterance analysis of language.
\end{abstract}

Keywords: Bilingualism, Color System, Ethnolinguistic Vitality Theory, Symbols, Language Attitude 


\section{Introduction}

There is no gain saying that bilingualism as a concept, and especially as a practice throughout the globe is now more a norm than an exception. Edwards (2013) claims this is true of many societies in the world today. Bilingualism is a nebulous concept, but it can be, on the surface, viewed as the ability to use two languages, while multilingualism is the concept of having more than two languages (Adegbite, 2003). Bilingualism is influenced by various factors that range from the physiological to the psychological and even to external factors such as politics, economics, etc. It is therefore not out of place to regard bilingualism and multilingualism as "highly complex and multidimensional linguistic, psychological, and social behaviors" (Butler, 2013). In explicating the concept of bilingualism, closely related to a language is the accompanying culture. In this sense, it is impossible to separate a language from the culture which it conveys (Sapir, 1929). Garcia (2011) opines that "a language divorced from its culture is like a body without a soul". In other words, languages rely on the underlying culture to make meaning.

Language itself is a complex concept to define. It is often viewed from the linguistic (spoken) perspectives alone. However, language is more holistically defined as a combination of signs (Saussure, 1916). These signs include varieties of spoken and nonspoken methods by which humans communicate. Examples of non-linguistic methods include: colors, clothing, gestures, inscriptions, etc. This study relies on the cultural significance of language and the universality of colors to study the perspective and attitude of bilinguals to their languages and culture(s). Color terms exist in all languages and convey meanings in significant forms (Suntharesan, 2016). These forms might be overt or subtle. However, the color system of each society is a reflection of the culture of that society. It is used for communication between individuals. For example, red in some cultures is an expression of danger; white implies peace and tranquility in some cultures; black is used to show mourning in some societies. Individuals collectively understand the signification of symbols within their society, so color systems are undoubtedly language systems. It can be inferred from all the above that the color system is a language form by which speakers of a language can express themselves. To a large extent, the same way as spoken utterance, gestures, and signs, attitudes, perspectives, feelings, emotions can be inferred through the color system.

Bilinguals have the command of at least two languages and so they perhaps, or perhaps not, view the world from two perspectives. Whichever the case may be, bilinguals are not cultural floaters and so they can view colors from at least one cultural angle. This universality of the concept of color makes it even a more reliable concept to measure the 
non-linguistic expressions of humans (Suntharesan, 2016). Bilinguals usually have differing perspectives and attitudes to the languages in their repertoire which usually stem from extra-linguistic factors such as culture, politics, economic opportunities, etc. As a universal language, colors would therefore be able to convey bilingual attitude and psychological system.

\subsection{Bilingualism: Language and Culture}

Culture consists of all the things that a person needs to know or believe to be able to behave in a way that is acceptable to members of a particular community or society (Goodenough, 1975). In other words, language exists in a manner that is intertwined with culture. This is fair enough to say, since language cannot exist in a vacuum and so must continually operate in a 'transfusion' with culture (Fairclough, 1989).

The understanding of the interaction between language and culture is necessary to understand the magnitude of the complexity of a typical bilingual mind. Butler (2013) categorizes bilingualism based on diverse points of focus. (1) Relationship between proficiencies in two languages (Balanced/Dominant- Peal and Lambert, 1962): according to Baker (2003), a balanced bilingual can use his or her multiple language for different purposes, with different interlocutors, and in different environments. Dominant bilingualism on the other hand is when an individual decides to master the diverse use of only one language usually influenced by the usage, domain and value of that language (Moradi, 2014). This balance in the proficiency of language is also affected by factors such as the age of the speaker, and the context of acquisition of languages. (2) Organization of linguistic codes and meaning units (Compound/ Coordinate/Subordinate- Weinreich, 1953). Moradi (2014) defines compound bilingualism as having two different linguistic codes within one system of word meaning. This single system is used for both languages; two distinct word labels or verbal expressions, for instance, might have a similar underlying representation across two languages (Heredia and Cieslicka, 2014). Coordinate bilingualism implies that the linguistic codes of a bilingual are stored in distinct systems used for operation (Bertram, Schreuder, and Bayeen, 2000). Subordinate bilingualism refers to having two linguistic codes, but only one unit of meaning (Moradi, 2014). In other words, a second language or any other subsequent ones are learned through the first language. Summarily according to Heredia and Cieslicka (2014), the learning contexts and acquisition opportunities of languages determine their storage- independently or dependently on another language. 
(3) Age of Acquisition (Early/Simultaneous/Sequential/Late- Genesee, Hammers, Lambert, Wallace, Mononen, Seitz, and Stark, 1978): this categorization is within individual multilingualism. This means an individual might be exposed to more than one language from birth and thus acquire them simultaneously or be exposed to a second and possibly additional languages later as he grows (Cenoz, 2013). (4) Effect of L2 learning on retention of L1 (Additive/Subtractive- Lambert 1974): this distinction is made at the societal level of language use. According to Cenoz (2013), additive bilingualism implies the addition of another language to a bilingual's repertoire while the first language is unhindered in development. In subtractive bilingualism however, a new language learnt replaces the first language. An important factor that affects such differentiation is being bilingual in languages that are demographically strong with a high status and a weaker language (Kramsch, 2010). (5) Functional ability (Receptive/Productive- Fishman, 1965): the distinction in the functional ability is defined in an individual's varying or similar use of multiple languages (Baker 2007; Engen and Kulbrandstad, 2004). Bilingualism is receptive or productive based on an individual's use in diverse domains, among different interlocutors and contexts (Serpa, 2014) or as Fishman in Baker (2007) puts it: "when, where, and with whom people use their two languages". (6) Language status and learning environment (Elite/Folk- Fishman, 1977): Elite bilingualism implies a voluntary choice to learn a new language with social prestige which leads to additive bilingualism; folk bilingualism on the other hand is associated with subtractive bilingualism and refers to the condition where individuals acquire a subsequent language and tend to lose a prior one because it has a low prestige in the environment of the individuals (Martin-Jones, 2007). (7) Cultural identity (Bicultural/L1 monocultural/L2 accultural/Deculturated- Hamers and Blanc, 2000): this has to do with the maintenance of the culture associated with a language. It might mean the acquisition of a language without its accompanying culture, or the acquisition of another language and culture which results in the loss of the culture of a prior language.

It is assumed that humans learn languages right from infancy, so it is often common to have early simultaneous bilinguals. When a child learns two languages together, such a child can be regarded as a simultaneous bilingual. McLaughlin (1984) would maintain that it is improper to categorize the languages of such a child as first and second languages. Since both languages are acquired at the same time, then it is only proper that they both be regarded as first languages. In Nigeria, a former British colony which is multilingual with 527 different languages (the Ethnologue, 2017), children acquire, right from their childhood, English language together with their native language(s) (Adegbite, 2003). Sequential bilingualism involves the acquisition of another language after one has been 
established. McLaughlin (1984) posits that the languages are clearly differentiated in this case so the added language can be regarded as the second language while the initial language is regarded as the first. Liddicoat (1991) explicates that simultaneous bilingualism does not necessarily imply more proficiency over sequential bilingualism, but still depends on other factors such as prestige of the acquired languages, continuous contact with the languages, etc.

\subsection{Color Perspectives}

Color as a system plays a great role in communication in various cultures. Going by Danesi (2004), "colors are, in effect, signs that we use to represent whatever we deem appropriate". Therefore, colors carry important messages when talking about culture or in the context of religion (Adegbite, 2003). While some colors have relatively similar meaning across a lot of languages such as white which means purity or peace (Suntharesan, 2016), other colors can have different interpretations across cultural lines (Adegbite and Adeniyi, 2014). Red, for instance might mean war and slaughter in one culture, but mean vitality and entertainment in another. Valberg (2001) and Bohon, Hermann, Hansen, and Conway (2016), in summary, posit that color categories are not universal but are shaped by specific or respective cultures.

As noted earlier, similarities of cultures vary from those that are very similar to those which are largely dissimilar. Adegbite and Adeniyi (2014) quote psychological views that reveal that colors can express the inner spirits of a person. Although color perceptions are quite subjective, effects are proven to have universal meaning. There are basically twocolor categories according to Berlin and Kay (1969): warm and cool. Warm colors evoke emotional effects ranging from warmth and comfort to anger and hostility. Colors in this category are red, orange and yellow. Colors in the cool category are blue, purple and green and these colors are said to portray calmness, but sometimes evoke mild feelings of sadness or indifference.

\subsection{Significance and Scope of Study}

Linguistic expressions are part of a larger system of language usage (Saussure, 1916). For this reason, interpretation of non-verbal expressions must be done using tools that take into consideration much more than ordinary spoken utterance. More to this is that spoken utterances greatly vary across cultures in terms of form, expression and functions. There is perhaps no single variety of spoken words that cuts across all cultures and 
languages of the world. For this reason, there is need to look into concepts which are general in communication to be able to do an analysis that would objectively apply to all cultures. Bilinguals do not possess simple language systems that monolinguals possess. According to Kroll and McClain (2013), they must constantly negotiate within two languages and maintain inhibitory control of linguistic interference that is not relevant. Analyzing a bilingual's attitude, for instance, through pure linguistic tools might therefore generate bias results that favor a language over another. If, however, a universally neutral tool as in color system is used in analysis, there is an excellent chance of having a viable result. Even though several societies have varying number of colors based on the terms with which they refer them according to their perception of colors, this research is viable because the two societies involved have similar knowledge of the color terms used. From the above, it can be affirmed that an analysis of the selected participants' bilingual's color system or preference will aid inferences about their perception and attitude to each of the languages in their repertoire and by extension, each accompanying culture or society.

The bilingual mind continues to shuttle within a complex ball of two languages even though the individual perception of each of the languages and its culture might vary. This study examines how the attitude of bilingual speakers to each of the languages, and their accompanying cultures, in their repertoire can be determined using their color preferences. The importance of this study is not only to provide meanings to the color terms but to also show that choice of colors does not just stem from an abstract connection of the brain to visual cues, but is as a result of conscious and unconscious association of the meaning of colors to their corresponding language.

Owing to language contact throughout the world, many bilinguals exist with varying types of languages in their linguistic repertoire. This study is limited to a contrast between Chinese- English bilinguals in Syracuse University, USA and Yoruba-English bilinguals in Obafemi Awolowo University, Nigeria. For a more plausible analysis, the study examines respondents who are students of English language in both institutions.

\subsection{Aim and Objectives}

To describe the perceptions of the bilingual mind of Yoruba-English and ChineseEnglish bilinguals using the universal concept of color, this study will:

a. analyze colors across various lines of preference by Yoruba-English and ChineseEnglish bilinguals, 
b. interpret colors in the context of geographical location, language acquisition and identity (gender, race, and age), and

c. describe language attitudes of respondents in terms of analyzed colors.

\subsection{Research Hypotheses}

a. Females will be more disposed to bright colors while males would have more preference for dark colors.

b. Chinese-English bilinguals, being in the United States, will manifest more positive attitude towards English than Chinese.

c. Yoruba-English bilinguals, being in Nigeria, notwithstanding their acceptance of English (which is the language of social mobility) will have a positive perception and pride for their native Yoruba language.

d. Choices of colors to represent each language will reflect the awareness of respondents, who are students, of the color representation system in English as it applies to their languages i.e., Yoruba and Chinese (Mandarin).

\subsection{Research Methodology}

The study adopts a purposive sampling technique, and the analysis is quantitative, qualitative and descriptive. The criteria for the selection of respondents were location, language repertoire, and academic qualification. Chinese-English bilinguals who resided in a foreign language community (USA) were selected to be contrasted with YorubaEnglish bilinguals who resided in their native language community (Ile-Ife, Nigeria). For a balance in their academic qualifications, undergraduates were selected in both contexts. The research instrument used for this study is a survey. Subjects were selected, 130 each, from Obafemi Awolowo University, Nigeria and Syracuse University, USA. The 130 respondents for each group of students were further split into 65 for females and 65 for males in each category. These subjects are Yoruba-English bilinguals in Nigeria, and Chinese-English bilinguals in the United States. The survey included questions that elicited biographical information as well as information as regards perception of colors. Nine major (9) colors namely: White, Grey, Black; Red, Orange, Yellow; Blue, Green, and Purple were grouped into three, based on Adegbite and Adeniyi (2014). The personal and research data were analyzed using statistics tools- EpiData and SPSS. 


\subsection{Theoretical Framework}

This study utilizes the framework of Ethnolinguistic Vitality Theory proposed by Giles, Bourhis and Taylor (1977). This framework examines the distinctiveness and peculiarity of a group in situations especially outside the group. It therefore takes into consideration an individual's identity which derives from their knowledge and selfconsciousness of their membership of a social group (Tajfel 1978). According to Adriosh and Razi (2016), Ethnolinguistic Vitality Theory (EVT) gives an insight into the importance and prestige associated to local languages and cultures as against other languages in a multilingual context. Through this, individuals' conception and attitude to their language(s) can be determined and utilized, on a larger scale, to project and evaluate the survival of languages and cultures in a multilingual context. According to Phinney (2003) cited in Adegbite (2016), Ethnolinguistic Vitality or Identity Theory represents a primary aspect of an individual's world view. In other words, a person's view of their language(s) and/or culture against that of others determines their language knowledge, preference and use.

An important aspect of this theoretical framework is language attitude. Defined as the subjective evaluation of language varieties and their speakers (Myers-Scotton, 2005), language attitude can be examined within an individual or a group. Various factors influence the attitude, positive or negative, of speakers of a language to that language in relation to others within a multilingual context, and these factors such as number of speakers, institutional support, language mobility strength, permeation by foreign languages, and domains of use generally dictate the cognitive basis of ethnolinguistic vitality (Adriosh and Razi, 2016).

In this study, color system which is a universal concept in social communication is analyzed in relation to language use and expression. As in Trudgil (2000) and Van Dijk (2009), language cannot be analyzed independent of its social context and other sociolinguistic contexts which must be taken into consideration. This study thus requires analyzing language as a form that is socially located within culture. In analysis therefore, there is consideration of the social background of interlocutors since it is believed that the analysis of the code itself and the cognitive process depends on the understanding of this fundamental social factor. In evaluating the choice of colors and languages which shows group identity in this research, the Ethnolinguistic Vitality Theory (EVT) is fitting for analysis. Considered variables also include social factors such as class, age, gender, etc. 


\section{Analysis and Findings}

\section{Demographic Information of Subjects}

A total of 260 surveys were analyzed. $130(50 \%)$ of the respondents were YorubaEnglish bilinguals and the other 130 (50\%) were Chinese English bilinguals. Chinese in this case encompassed all recognized 'varieties' of Chinese. Furthermore, there were 130 (50\%) females (65 Chinese and 65 Yoruba) and 130 males (65 Chinese and 65 Yoruba). $193(74.2 \%)$ of the respondents were aged $18-21$ years; 10 (3.8\%) were $15-17$ years; 51 (19.6\%) were between 22-25 years while 6(2.3\%) were between 26-30 years. The predominance of ages 18-21 among the respondents was because respondents were selected from the University. Most of them were either first- or second-year undergraduates so the ages are normal and expected.

Out of the $130(100 \%)$ Chinese bilinguals in the United States, $125(96.2 \%)$ had been in the United States for 5 years or less, 3 (2.3\%) had been in the United States for more than 5 but less than 10 years while $1(0.8 \%)$ had been in the United States for more than 10 years but below 15 and the same number had been in the United States for more than 15 years. The fact that a lot of the Chinese-English bilinguals were in the United States to study and were still in their starting years was a major reason why an overwhelming 125 (96.2\%) had only been in the United States for less than 5 years. In fact, most of them had been in the US for just 1 or 2 years.

Of all the respondents, 137 (52.7\%) (the Yoruba-English bilinguals being the overwhelming majority in this category) acquired English between ages 1-5; 97(37.3\%) learned English between ages 6-10; 24(9.2\%) learned it between ages 11-18 while $2(0.8 \%)$ learnt it after 19 years. While $5(1.9 \%)$ failed to report how many languages were in their repertoire, 197(75.8\%) spoke 2 languages while 58 (22.3) spoke 3 languages (which included different local and foreign languages such as Igbo, Cantonese, French, Arabic, etc. The Yoruba-English bilinguals were in a society where English is used as language of governance and official communication which explains why all of them were simultaneous bilinguals. However, the Chinese mainly used their native languages in China without any access to English till they came over to the United States or were sent to English schools in China. This explains why majority of the Chinese learned English after age 6. The research was conducted on bilinguals which automatically translates to all respondents speaking 2 languages, at least. 


\subsection{Favorite Colors}

The favorite colors selected by respondents were analyzed along the lines of ethnicity and also the lines of gender.

Table 1. Favorite Colors

\begin{tabular}{|c|c|c|c|c|c|c|c|c|c|c|c|c|}
\hline \multirow[t]{2}{*}{ Gender } & & & \multicolumn{9}{|c|}{ Favorite color } & \multirow[t]{2}{*}{ Total } \\
\hline & & & White & Grey & Black & Red & Orange & Yellow & Blue & Green & Purple & \\
\hline \multirow{3}{*}{ Male } & \multirow{2}{*}{ Nationality } & Nigerian & 16 & 3 & 15 & 10 & 2 & 1 & 13 & 3 & 1 & 64 \\
\hline & & Chinese & 15 & 7 & 15 & 4 & 4 & 1 & 12 & 5 & 1 & 64 \\
\hline & \multicolumn{2}{|l|}{ Total } & 31 & 10 & 30 & 14 & 6 & 2 & 25 & 8 & 2 & 128 \\
\hline \multirow{3}{*}{ Female } & \multirow{2}{*}{ Nationality } & Nigerian & 8 & 5 & 4 & 5 & 2 & 4 & 13 & 4 & 8 & 53 \\
\hline & & Chinese & 14 & 6 & 12 & 6 & 2 & 2 & 10 & 3 & 2 & 57 \\
\hline & \multicolumn{2}{|l|}{ Total } & 22 & 11 & 16 & 11 & 4 & 6 & 23 & 7 & 10 & 110 \\
\hline \multirow{3}{*}{ Total } & \multirow{2}{*}{ Nationality } & Nigerian & 24 & 8 & 19 & 15 & 4 & 5 & 26 & 7 & 9 & 117 \\
\hline & & Chinese & 29 & 13 & 27 & 10 & 6 & 3 & 22 & 8 & 3 & 121 \\
\hline & \multicolumn{2}{|l|}{ Total } & 53 & 21 & 46 & 25 & 10 & 8 & 48 & 15 & 12 & 238 \\
\hline
\end{tabular}

A total of $238(91.5 \%)$ respondents selected one out of the 9 provided colors as their favorite color, $22(8.5 \%)$ selected either the 'other' option or failed to respond. Most of those who selected the 'other' option were females and 16 of the 22 who selected 'other' chose color Pink. The other two listed colors were Peach and Gold, each selected by two respondents.

In summary, out of the $128(100 \%)$ colors selected by males, white was the most selected with $31(24.2 \%)$ respondents. Black- 30 (23.4\%), blue-25(19.5\%) and red$14(10.9 \%)$ were also frequently identified as favorite colors. Orange-6(4.7\%), yellow-2 $(1.6 \%)$, and purple-2 $(1.6 \%)$ were the least identified favorites. In the female category a total of 126 selected a color out of the provided options or wrote another in the 'other' 
category. Out of the $110(100 \%)$ that chose one of the provided colors, 23 (20.9\%), 22 $(20.0 \%), 11(10 \%)$, and 11(10\%) selected blue, grey and red respectively. Pink was selected 16 times (12.6\% of the 126 who selected a favorite color). The least selected colors were yellow and orange: $6(5.5 \%)$ and $4(3.6 \%)$ respectively. The colors were then divided into two categories:

a. Bright: White, Red, Orange, Yellow, Purple, Peach, Gold and Pink.

$b$. Dull: Grey, Black, Blue, and Green.

In the male category; out of $128(100 \%)$ respondents, $55(43 \%)$ selected a bright color while $73(57 \%)$ selected a dull color. Amidst females however, out of the 130(100\%) overall respondents (those who selected out of 9 provided colors or wrote in the 'other' category), 73 (56\%) chose bright colors while 57 (44\%) selected dull colors. From the forgoing, even though the gap is not overwhelming, it can be concluded that females had more preference for bright colors than males.

Analysis was then done in terms of nationality. In Nigeria, 30 (46\%) of 64 male respondents selected bright colors while $34(54 \%)$ chose dull colors. Amidst the females; out of the 65 respondents, 39 (60\%) chose bright colors while 26(40\%) preferred a dull one. This shows that in the Nigerian context, females have more preference for bright colors and males, for dull ones. In China however, 25 (39\%) of 64 male respondents selected bright colors while 39 (61\%) chose dull colors. Amidst the females; out of the 65 respondents, $34(52 \%)$ chose bright colors while $31(48 \%)$ preferred a dull one. By implication, Chinese males preferred dull colors to bright ones, but Chinese females do not show such clear preference. Even though there is relative preference for bright colors at $52 \%$ to $48 \%$ for bright and dull colors respectively, Chinese females make it too close to call.

\subsubsection{Language Attitude}

Before surveys were designed, the researcher had personal consultations with respondents and non-respondents who were natives of the respective cultures about their thoughts on the signification of colors in their respective cultures. The consultations were not in research or official conditions, but casual situations to ensure the viability of responses. These consultations influenced the design of the survey which also included questions regarding their knowledge of the signification of various colors in their respective cultures to double check the previous consultations. Assertions about the signification of colors in the two selected societies are therefore based on overwhelming responses to empirical enquiries and consultation of a wide spectrum of individuals from 
the respective cultures of the selected respondents. The selected basic colors had largely the same connotation across the two cultures. The only slight diversity was in the use of color red by the two cultures respectively. Although the connotation of love was general to the two cultures, the Yoruba perceived red to signify danger in addition, while the Chinese perceived red to also symbolize Happiness and Pride.

Table 2. Mother Tongue Color

\begin{tabular}{|c|c|c|c|c|c|c|c|c|c|c|c|c|}
\hline & & & \multicolumn{9}{|c|}{ Color (MT) } & \multirow[t]{2}{*}{ Total } \\
\hline & & & White & Grey & Black & Red & Orange & Yellow & Blue & Green & Purple & \\
\hline \multirow{4}{*}{ Nationality } & \multirow{2}{*}{ Nigerian } & Count & 52 & 0 & 11 & 35 & 0 & 1 & 17 & 10 & 4 & 130 \\
\hline & & $\%$ of Total & $20.0 \%$ & $0.0 \%$ & $4.2 \%$ & $13.5 \%$ & $0.0 \%$ & $0.4 \%$ & $6.5 \%$ & $3.8 \%$ & $1.5 \%$ & $50.0 \%$ \\
\hline & \multirow{2}{*}{ Chinese } & Count & 13 & 4 & 3 & 91 & 4 & 7 & 7 & 1 & 0 & 130 \\
\hline & & $\%$ of Total & $5.0 \%$ & $1.5 \%$ & $1.2 \%$ & $35.0 \%$ & $1.5 \%$ & $2.7 \%$ & $2.7 \%$ & $0.4 \%$ & $0.0 \%$ & $50.0 \%$ \\
\hline \multirow{2}{*}{ Total } & & Count & 65 & 4 & 14 & 126 & 4 & 8 & 24 & 11 & 4 & 260 \\
\hline & & $\%$ of Total & $25.0 \%$ & $1.5 \%$ & $5.4 \%$ & $48.5 \%$ & $1.5 \%$ & $3.1 \%$ & $9.2 \%$ & $4.2 \%$ & $1.5 \%$ & $100.0 \%$ \\
\hline
\end{tabular}

There were $260(100 \%)$ total respondents. Out of 130 (50\%) Nigerians, $52(20 \%)$ selected white as the color to represent their mother tongue, $35(13.5 \%)$ selected red while $17(6.5 \%)$ selected blue. White, yellow, blue, green and purple reflected a positive attitude as respondents interpreted them to mean purity/dignity, brightness, calmness, fertility and royalty respectively. However, the bulk of the $35(13.5 \%)$ and $11(4.2 \%)$ that selected red and black respectively presented the Yoruba language, their MT, as being dangerous or harmful to their acquisition of English language or as backward and crude in development.

Out of the 130 Chinese respondents, 91 (35\%) selected red to symbolize pride, love and happiness for their language and culture. $13(5.0 \%)$ respondents selected white which symbolized peace and purity while $7(2.7 \%)$ respondents selected yellow and blue each to symbolize brightness and calmness respectively. Purple and green were least significant and was selected by none and one person respectively. However, 4 (1.5\%) and $3(1.2 \%)$ Chinese-English bilinguals selected grey and black to symbolize their Mother Tongue, Chinese, as being a hindrance to their learning English language or to their progress in life. 
Table 3. Second Language Color

\begin{tabular}{|c|c|c|c|c|c|c|c|c|c|c|c|c|}
\hline & & & \multicolumn{9}{|c|}{ Color (2nd) } & \multirow[t]{2}{*}{ Total } \\
\hline & & & White & Grey & Black & Red & Orange & Yellow & Blue & Green & Purple & \\
\hline \multirow{4}{*}{ Nationality } & \multirow{2}{*}{ Nigerian } & Count & 42 & 0 & 10 & 30 & 0 & 2 & 36 & 4 & 4 & 128 \\
\hline & & $\%$ of Total & $16.3 \%$ & $0.0 \%$ & $3.9 \%$ & $11.7 \%$ & $0.0 \%$ & $0.8 \%$ & $14.0 \%$ & $1.6 \%$ & $1.6 \%$ & $49.8 \%$ \\
\hline & \multirow{2}{*}{ Chinese } & Count & 21 & 6 & 13 & 8 & 19 & 8 & 43 & 8 & 3 & 129 \\
\hline & & $\%$ of Total & $8.2 \%$ & $2.3 \%$ & $5.1 \%$ & $3.1 \%$ & $7.4 \%$ & $3.1 \%$ & $16.7 \%$ & $3.1 \%$ & $1.2 \%$ & $50.2 \%$ \\
\hline \multirow{2}{*}{ Total } & & Count & 63 & 6 & 23 & 38 & 19 & 10 & 79 & 12 & 7 & 257 \\
\hline & & $\%$ of Total & $24.5 \%$ & $2.3 \%$ & $8.9 \%$ & $14.8 \%$ & $7.4 \%$ & $3.9 \%$ & $30.7 \%$ & $4.7 \%$ & $2.7 \%$ & $100.0 \%$ \\
\hline
\end{tabular}

In total, $84(65 \%)$ Nigerians selected colors that symbolize a positive attitude of peace, fertility, calmness and royalty while 46(35\%) selected colors i.e. red and black that symbolize danger and backwardness. However, some selected the two colors to mean beauty and love for their Language. On the flip side, 123(97\%) of Chinese-English bilinguals selected colors that symbolized a positive attitude of pride, dignity, brightness, calmness and fertility towards their native language. Only $7(3 \%)$ had a negative attitude of Chinese symbolizing uncertainty and backwardness. The discovery here is that a very negligible $3 \%$ of Chinese had a negative attitude towards their MT while a significant 35\% of Yoruba-English bilinguals had a negative attitude towards their native language.

Out of 129 Chinese-English bilinguals, 102(79\%) selected colors that symbolized dignity, warmness, fertility and globalization for English while 27(21\%) regarded it as evil, uncertain and dangerous. Worthy of being noted is that when it came to the second language, English, Chinese-English bilinguals switched from their meaning of red for the MT which was pride and used red to rather symbolize danger. While it is the case among both bilinguals that they had positive attitude towards English, Chinese-English bilinguals still had more resistance to English than Yoruba-English bilinguals showed. 
Table 4. Third Language Color

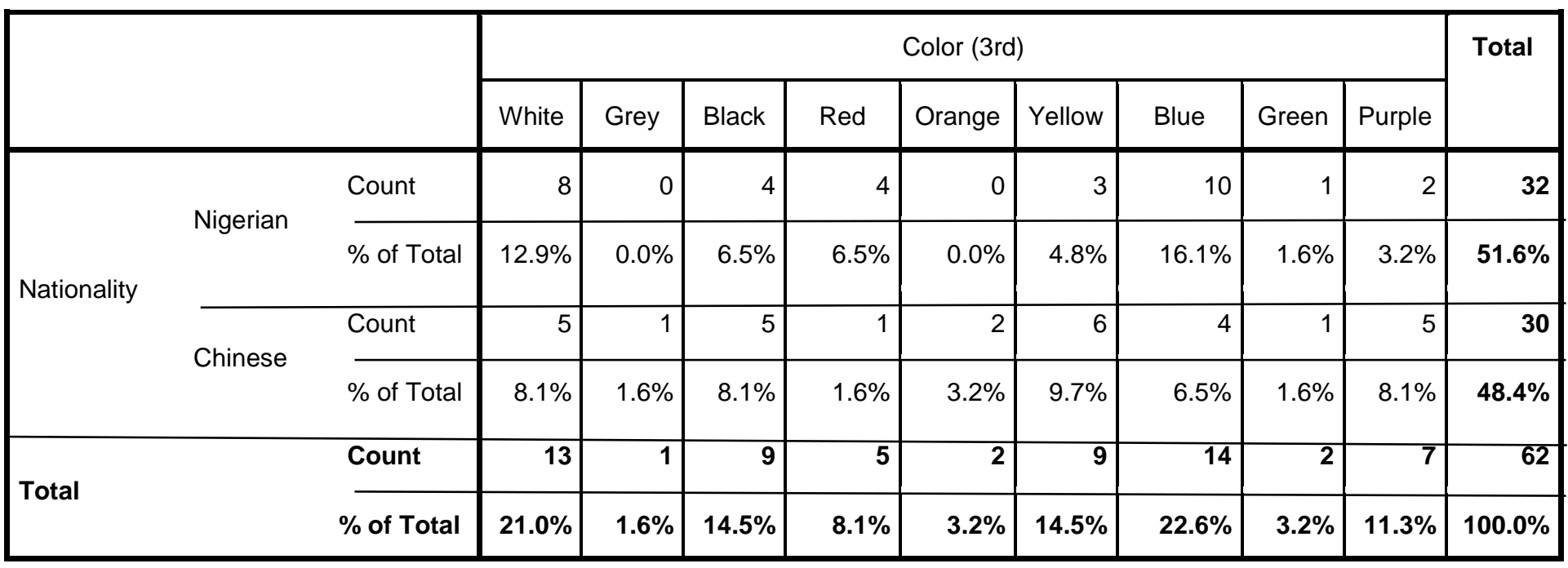

A total of $62(100 \%)$ claimed to speak a third language. Among Yoruba English bilinguals, the attitude towards their third language such as French, German, Igbo, Hausa, etc. was generally positive. Those who selected red meant it to symbolize their love for the third language. Only about $4(7 \%)$ of the total 62 had reservations about their third language to either be a language of underdevelopment or evil. Those 4 respondents meant indigenous Nigerian languages such as Igbo and Hausa. The Chinese-English bilinguals generally had a positive disposition to their third languages such as German, Korean, Japanese, Spanish, etc. Only about 2(7\%) who selected grey and black had an uncertain disposition to their third language. Others who selected black meant it to mean 'a secret power' that they possessed in their repertoire.

\section{Discussion of Findings}

Literature suggest that relationship between color and language is complex and that such perception may be shaped by relativistic and universal forces ( $\mathrm{He}, \mathrm{Li}, \mathrm{Xiao}$, Jiang, Yang, and Zhi, 2019). This supports the present study in that while speakers generally had a positive evaluation of colors such as white, they differ in their evaluation and subsequent assignment of other colors such as red and black to their languages. According to the Whorf 
hypothesis, the repertoire of a people can have an impact on their cognition (Whorf and Caroll,1956). Although, not much has been done on the evaluation of speakers' language based on their knowledge of the color system, many scholars have researched the relationship between color perception and language as well as color perception and cognition (Kay and Kempton, 1984; Davidoff, 2001; Winawer, Withoft, Wu and Boroditsky (2003); Roberson, Davidoff, Davies and Shapiro, 2005). For example: Winawer et al. show there is an on-line effect of verbal coding on color discrimination. We can infer the application of this finding in the current research where the evaluation of respondents' languages is based on their perception of the colors in the color system of their native environment.

Some of the formulated hypotheses at the beginning of this study were confirmed while others were nullified. In terms of preference for colors, it was confirmed that males generally had more preference for dull colors than females who mostly preferred bright colors. However, this assertion was not overwhelmingly true in the case of Chinese females who had a very tight margin between their preference for bright colors and that for dull colors. White and Blue were emphasized as colors that had popularity of preference across the two genders in the two cultures.

As opposed to the hypothesis, Chinese English bilinguals, though in an English Language environment actually had an overwhelmingly more positive attitude to Chinese than they did to English. A major reason for this would be the earlier stated fact that majority of these respondents are sequential learners of English language and so learnt English after their Chinese had been fully established. In addition to this, majority of the Chinese-English bilinguals had had to use Chinese in all domains back in China without having any need for English whatsoever. This has helped in building their commitment to the language and pride in it. Another factor to note is that a lot of the Chinese-English bilinguals learned English only in an academic environment and basically have to use the language because they are in the United States for their Education. They thus see it as a language which they have to learn by force to be able to function in the American society. Lastly, China practices a communist system of government and their native language plays an important role in communication and survival in the society. This is unlike the case with Nigeria where native languages are subordinate to English in official and government functions.

Despite being in the native Yoruba environment, Yoruba-English bilinguals had a higher preference for English language than they did for their native Yoruba. Many of them perceive Yoruba language to be a language of backwardness while others perceived it to be a hindrance to learning English. They saw English to be a language of Globalization 
and that of Pride and Dignity. The reason is not farfetched: all Yoruba-English respondents were simultaneous bilinguals and coupled with this fact is that they lived in a society where English is the language of Social mobility. In other words, fluency in English is more desirable than fluency in Yoruba language. Also because of the level of education of the masses, a lot of people believe that competence in Yoruba prevents competence in English language hence the thought of Yoruba as a danger to the acquisition of English. Even though the Yoruba language conveys the culture and tradition of the Yoruba people, English controls the class placement of individuals in Nigeria as a whole. This situation is not exclusive to Nigeria alone, but similar in Anglo-West African states. In fact, it is the case in many other African countries.

In general, although there existed some diversity, respondents showed a great awareness of the symbolism of colors. They were even able to manipulate this symbolism across divides as in Chinese-English bilinguals who selected Red to mean Pride when it was for the MT and selected the same Red to mean danger when it was for English. Indeed, color system turned out to be a viable and largely accurate way of knowing the attitude of bilinguals to their different languages and society.

\section{Recommendations}

This study makes a comparison between Chinese-English bilinguals in an English language environment and Yoruba-English bilinguals in a Yoruba environment. In further studies, comparison could be made between the same set of bilinguals e.g. Yoruba-English bilinguals in Yoruba environment versus Yoruba-English bilinguals in English language environment. The result of such study can be compared with this study to see if a similar group of bilinguals can have different linguistic attitudes based on their location. Also, more bilingual groups can be compared to further strengthen the argument that is presented in this study.

In addition, further studies depending on the cultures or societies being compared, and the colors being utilized might require the use of visual aids in addition to surveys and personal conversation/observation. The methodology of this study is viable for the results obtained therein because respondents were aware of the colors that were utilized and have good knowledge of the signification of these colors in their societies. This is largely because the utilized colors were devoid of complex shades which would have complicated respondents' knowledge of the color system, and as such required the use of pictures or other visual aids for respondents to identify the shades of colors. 


\section{Conclusion}

The Ethnolinguistic Vitality Theory is very much applicable to beyond ordinary spoken utterance analysis of language. This study shows that colors are indeed a universal concept and can be used to express not only explicit information but also implicit information such as attitude and perspectives of individuals. Social context affects perception about language, and language is not valued only based on its linguistic or semantic components. The attitude of people to language is, a lot, determined by their allegiance to the underlying culture of that language as well as the usefulness of the language in terms of upward mobility in its resident social community.

Age and mode of acquisition of languages also play a part in a person's attitude towards different languages. Simultaneous bilinguals shift between their two languages depending on which one is more viable in culture and for social growth, but sequential bilinguals (especially those who acquire the second language at teen-age or above) have preference for their first language. This is ideally the case for sequential bilinguals unless there is a traumatic reason for a switch, or the first language is no longer relevant for opportunities which the bilingual craves. Even at that, there is bound to be a sentimental attachment to the first language.

\section{References}

Adegbite, Adegbite (2003). Multilingualism and National Development. In 'Lekan Oyeleye \& Moji Olatunji (Eds.). Readings in Language and Literature (First Edition), 153-167. Ile-Ife: OAU Press.

Adegbite, Adegbite (2014). A Semiotic Analysis of Inscriptions on the T- Shirts of Students from Selected Universities in Southwest Nigeria. Paper presented at the $14^{\text {th }}$ International Pragmatics Conference, Antwerp, Belgium. July 26-31, 2015.

Adegbite, Adegbite (2016). Language Policy and National Integration: A Case Study of Language Identity and Attitudes of Staff of Adekunle Aja sin University, AkungbaAkoko, Nigeria. In Akin Odebunmi and Kehinde Ayoola (Eds). Language, Context and Society: A Festchrift for Adegbite Adegbite. 417-439. Ile-Ife: OAU Press.

Adriosh, Mohamed and Razi, Ozge (2016). Investigating Nigerian University Students' Perception Towards English Language Dominance over their Indigenous Languages. The Eurasia Proceedings of Educational and Social Sciences (EPESS), 2016. Volume 5, 206-213. 
Baker, C. (2003). Foundations of bilingual education and bilingualism. 5th ed. Clevedon England: Multilingual Matters Ltd.

Baker C. (2007). A Parents and Teachers Guide to Bilingualism. Clevedon: Multilingual Matters Ltd.

Bell, R. T. (1976). Sociolinguistics: Goals, Approaches and Problems. London: Batsford.

Berlin B, Kay P (1969). Basic Color Terms: Their Universality and Evolution. Berkeley: University of California Press.

Bertram, R., Schreuder, R., and Bayeen, R (2000). The balance of storage and computation in morphological processing: The role of word formation type, affixal homonymy and productivity. Journal of Experimental Psychology. Learning, Memory and Cognition 26: 489-511

Bohon, K.S; Hermann, K.L; Hansen T; Conway, B.R. (2016). Representation of perceptual color space in macaque posterior inferior temporal cortex (the V4 complex). E Neuro 3:1-28

Butler, Yuko (2013). Bilingualism/ Multilingualism and Second-Language Acquisition in Tej K. Bhatia \& William C. Ritchie (Eds.). The Handbook of Bilingualism and Multilingualism (Second Edition), 5-25. Malden, MA: Wiley-Blackwell.

Cenoz, Jasone (2013). Defining Multilingualism. In Annual Review of Applied Linguistics. DOI: $10.1017 / \mathrm{S} 026719051300007 \mathrm{X}$

Danesi, M. (2004). Messages, Signs and Meaning: A Basic Textbook in Semiotics and Communication Theory. Toronto: Canada Scholars Press.

Davidoff, J. (2001). Language and perceptual categorization. Trends in Cognitive Sciences,5(9), 382-387.doi:10.1016/s1364-6613(00)01726-5

Edwards, John (2013). Bilingualism and Multilingualism: Some Central Concepts. In Tej K. Bhatia \& William C. Ritchie (Eds.). The Handbook of Bilingualism and Multilingualism (Second Edition), 5-25. Malden, MA: Wiley-Blackwell.

Engen T. \& Kulbrandstad L. (2004). Tospråklighet, minoritetsspråk og minoritetsundervisning. Oslo: Gyldendal Norsk Forlag.

Fairclough, N. (1989) Language and Power, Harlow Longman.

Genesee, Fred; Hammers, Josiane; Lambert, Wallace E; Mononen, L.; Seitz, M. and Stark, R. (1978). Language processing in bilinguals. Brain and Language 5:1-12.

Giles, H., Bourhis, R. Y., \& Taylor, D. M. (1977). Towards a theory of language in ethnic group relations. Language, ethnicity and intergroup relations, 307348.

Goodenough, W.H. (1957). Cultural anthropology and linguistics. Washington; Georgetown University Press. 
He, Hu; Li, Jie; Xiao, Qianguo; Jiang, Songxiu; Yang, Yisheng; and Zhi Sheng (2019). Language and Color Perception: Evidence From Mongolian and Chinese Speakers. Frontiers in Psychology. Vol. 10: 551. DOI=10.3389/fpsyg.2019.00551

Heredia, R., Cieslicka, A. B. (2014). Bilingual Memry Storage: Compound- Coordinate and Derivatives. Department of Psychology and Communications, 6, 11-20. doi: 10.1007/978-4614-9218-4

Kay, P., \& Kempton, W. (1984). What Is the Sapir-Whorf hypothesis? American Anthropologist, 86(1), 65-79. doi:10.1525/aa.1984.86.1.02a00050

Kramsch, C. (2010). The multilingual subject. Oxford, UK: Oxford University Press

Kroll, J.F and McCain, R. (2013). What bilinguals tell us about culture, cognition, and language. Proceedings of the National Academy of Sciences of the United States of America, 110, 11219-11220.

Lambert, Wallace E. (1974). Culture and language as factors in learning and education. In Frances E. Aboud and Robert D. Meade (Eds.). Cultural Factors in Learning and Education. 91-122. Bellingham, WA: Western Washington State University.

Liddicoat, Anthony (1991). Bilingualism: An Introduction. Bilingualism and Bilingual Education. NLIA Vol 2. Australia.

Martin-Jones, M. (2007). Bilingualism, education and the regulation of access to language resources. In Heller, M. (Ed.), Bilingualism: A social approach (pp. 161-182). New York: Palgrave Macmillan

McLaughlin, M. L. (1984). Conversation. Beverly Hills: Sage.

Moradi, H. (2014). An investigation through different types of bilinguals and bilingualism. Retrieved from https://www.ijhsss.com/files/Hamzeh-Moradi_6813z4a4.pdf

Myers-Scotton, C. (2005). Multiple voices: An introduction to bilingualism. Wiley Blackwell.

Peal, E., \& Lambert, W. E. (1962). The relation of bilingualism to intelligence. Psychological Monographs: General and Applied, 76(27, Whole No. 546), 23.

Phinney, J. (2003) Ethnic Identity and Acculturation. In K. Chum, P.B. Organists and G. Marin (eds). Acculturation Advances in Theory, Measurement and Applied Research. Washington DC: American Psychological Association, pp. 63-81.

Ramos Garcia, Ana Maria (2011). The Cultural Knowledge of Monolingual and Bilingual Students. In Daniel Madrid and Stephen Hughes (Eds), Studies in Bilingual Education. 8: 223-235. Bern/New York: Peter Lang. 
Roberson, D., Davidoff, J., Davies, I. R., \& Shapiro, L. R. (2005). Color categories:

Evidence for the cultural relativity hypothesis. Cognitive Psychology, 50(4), 378411. doi:10.1016/j.cogpsych.2004.10.

Sapir, E. (1929). Language. New York: Harcourt Brace.

Saussure, F. de. (1916). Course in general linguistics (C. Bally \& A. Sechehaye, Eds; R. Harris, Trans). London: Duckworth.

Saville-Troike. (2003), The Ethnography of Communication. Oxford: Blackwell.

Serpa, Livia Amdrea (2014). Children Language Acquisition Focusing on Bilingualism. A Master's thesis submitted to the faculty of Educational Sciences, University of Oslo, Norway.

Simons, Gary F. and Charles D. Fennig (Eds). 2017. Ethnologue: Languages of the World (Twentieth edition). Dallas: SIL International. http://www.ethnologue.com.

Spolsky, B. (2010). Ferguson and Fishman: Sociolinguistics and the sociology of language. In R. Wodak, B. Johnstone, \& P. Kerswill (Eds.), The Sage handbook of sociolinguistics (pp. 11-23). Los Angeles: SAGE.

Suntharesan, V. (2016). Color Terms in Languages. Language in India. Vol. 16 (2). ISSN: 1930-2940.

Tajfel, H. E. (1978). Differentiation between social groups: Studies in the social psychology of intergroup relations. Cambridge, MA: Academic Press.

Trudgill, Peter. (2000), Sociolinguistics: An Introduction to Language and Society. England: Penguin Books. (p.122)

Valberg, A. (2001). Unique hues: An old problem for a new generation. Vision Research, 41(13), 1645-1657. http://dx.doi.org/10.1016/S0042-6989(01)00041-4

Van Dijk, Teun A. (2009). Society and Discourse: How Social Contexts Influence Text and Talk. Journal of Languages and Politics. Vol 9(3). Sheffield Hallam University. DOI: 10.1075/jlp.9.3.07lam

Winawer, J., Witthoft, N., Frank, M. C., Wu, L., Wade, A. R., \& Boroditsky, L. (2007). Russian blues reveal effects of language on color discrimination. Proceedings of the National Academy of Sciences of the United States of America,104(19), 7780-7785. doi:10.1073/pnas.0701644104

Weinreich, Uriel (1953). Languages in Contact. The Hague: Mouton

Whorf, B. L., \& Carroll, J. B. (1956). Language, thought, and reality: Selected writings of Benjamin Lee Whorf (Vol. 5). Cambridge, MA: MIT Press 